\title{
Produção de texto no contexto da progres- são dos gêneros textuais: proposições do livro didático
}

\author{
Jéssica Pereira da Silva \\ Débora Amorim Gomes da Costa-Maciel \\ Universidade de Pernambuco
}

\section{Resumo}

presente artigo analisa a produção de texto no livro didático de Língua Portuguesa, com vistas a investigar as estratégias de progressão nas atividades propostas. Toma-se como aporte teórico o conceito de progressão discutido por Dolz e Schneuwly (201 1); o estudo da progressão escolar e do ensino de produção de texto realizado por Leal e Brandão (2007; bem como as concepções de produção textual abordadas por Geraldi (2010); Guedes (2009) e por Koch (2003). Em se tratando da tipologia da pesquisa, trata-se de uma abordagem qualitativa, de base interpretativa. A obra didática investigada apresenta um trabalho com a escrita de modo sistematizado e sob o viés da progressão textual. Em suma, acredita-se que analisar a progressão nas atividades de produção textual do livro didático pode contribuir de maneira significativa para o ensino sistemático da escrita.

Palavras-chave: Produção de texło. Progressão de gêneros textuais. Livro didático.

\section{Text production in the context of progression of textual genres: pro- positions of textbook}

\begin{abstract}
This article analyzes the text production in textbook Portuguese language, in order to investigate the progression of strategies in the proposed activities. Taking as theoretical support the concept of progression discussed by Dolz e Schneuwly (2011), the study of school progression and text production of teaching made by Leal and Brandão (2006); as well as textual production concepts addressed by Geraldi (2010), by Guedes (2009) and by Koch (2003). When it comes to the typology of the research, it is a qualitative approach, on interpretative basis. The didactic work investigated presents a work with the writing in a systematic way and under the bias of textual progression. In short, it is believed that analyzing the progression in the activities of textual production of textbooks can contribute significantly to the systematic teaching of writing.
\end{abstract}

Keywords: Textual production. Progression. Textbook of Portuguese Language. 


\section{Producción de texto en el contexto de progresión de géneros textua- les: proposiciones del libro didáctico}

\section{Resumen}

El presente artículo analiza la producción de texto en el libro didáctico de Lengua Portuguesa, con el objetivo de investigar las estrategias de progresión en las actividades propuestas. Se toma como referencia teórico el concepto de progresión discutido por Dolz y Schneuwly (2011); el estudio de la progresión escolar y de la enseñanza de producción de texto realizado por Leal y Brandão (2006); bien como las concepciones de producción textual abordadas por Geraldi (2010), Guedes (2009) y por Koch (2003). Acerca de la tipología de la pesquisa, se trata de un abordaje cualitativa de base interpretativa. La obra didáctica investigada presenta un trabajo con la escrita de modo sistemático y con enfoque en la progresión textual. En síntesis, se cree que analizar la progresión en las actividades de producción textual del libro de texto pode contribuir de manera significativa para la enseñanza sistemática de la escrita.

Palabras clave: Producción de texło. Progresión. Libro didáctico.

\section{Introdução}

Ensinar a produzir textos certamente não é uma tarefa fácil, uma vez que a atividade de escrita envolve aspectos de natureza linguística, cognitiva, pragmática, sócio-histórica e cultural (KOCH; ELIAS, 2015, p. 34). $\bigcirc$ ensino da escrita envolve a "[...] ativação de conhecimentos prévios sobre os componentes da situação comunicativa [...]"; seleção e organização de ideias a fim de garantir o prosseguimento do tema e a sua progressão; organização entre ideias explicitas, implícitas, "novas" e "dadas" informações; revisão e reescrita em função dos objetivos visados (KOCH; ELIAS, 2015, p. 34). Portanto, o professor necessitará refletir, sistematicamente, sobre as estratégias necessárias para fazer com que os alunos sejam produtores autônomos de textos.

Pensar no sujeito autônomo, à luz da concepção interacional da língua, implica ressignificar a presença das atividades de escrita em que se privilegia a reprodução de frases e textos, exercícios de codificação e de decodificação, atividades com frases soltas para identificação de determinada classe gramatical etc. A perspectiva teórica, defendida neste texto, convoca a prática significativa de produção textual seja uma produção escolar, como, por 
exemplo, a confecção de textos identificados por Beth Marcuschi e Cavalcante (2005) e Dolz e Schneuwly (20 11 ) de "redação escolar" ou de uma produção que considere a diversidade de gêneros em que circulam outras esferas.

trabalho com a produção textual deve levar em consideração o contexto em que se realiza a escrita; o que se escreve, para quem escreve e para que se escreve. Estão em jogo, nesse processo construtor, as condições de produção que dá visibilidade ao contexto de produção e de realização do gênero. Entende-se que um caminho possível para um ensino significativo da escrita seja a opção pelo ensino de produção textual sob o viés da progressão dos gêneros textuais, já que se trata de uma estratégia validade no campo da ciência para o ensino da produção de texto, imerso no campo dos gêneros e nos diferentes domínios de comunicação do discurso (DOLZ; SCHNEUWLY, 20111 .

Para Dolz e Schneuwly, a progressão compreende a sistematização temporal de ensino, capaz de propiciar uma aprendizagem em espiral. Como estratégia de ensino visando à progressão, os autores propõem o agrupamento dos gêneros de acordo com os domínios sociais de comunicação do discurso, como, por exemplo, a partir da ordem do narrar, do relatar, do argumentar etc. Dessa forma, o ensino a partir do agrupamento de gêneros propicia a elaboração de uma progressão que trata "[...] de construir, com os alunos, em todos os graus de escolaridade, instrumentos, visando ao desenvolvimento das capacidades necessárias para dominar os gêneros agrupados" (DOLZ; SCHNEUWLY, 2011 , p. 221.

Com relação aos gêneros, a discussão sobre a progressão passa a ser também assumida pelos referenciais teóricos que aportam alguns livros didáticos, na medida em que se observa que tal estratégia pode colaborar para melhor desenvolver trabalhos sistemáticos e planejados para o ensino da Língua Portuguesa nos diferentes eixos didáticos. $\bigcirc$ livro analisado traz em sua fundamentação teórica que pretende

Conceber a progressão do conteúdo em espiral, sendo previsto trabalho em cada ano com gêneros de diferentes agrupamentos evoluindo em complexidade, tanto no que se refere aos agrupamentos de gêneros selecionados, como no que diz respeito às habilidades (DELMANTO; CARVALHO, 2012, p. 15). 
Nessa perspectiva, o presente trabalho investiga a progressão textual no contexto das propostas de produção de textos presentes no livro didático "Jornadas.port", de Dileta Delmanto e Laiz B. de Carvalho - do $9^{\circ}$ ano do Ensino Fundamental. A escolha da obra se dá pelo fato de ser uma obra didática que anuncia no manual direcionado ao Professor que se fundamenta no conceito de Progressão Textual delineado por Dolz e Schneuwly (20 1 1), objeto de estudo desse trabalho. Somada a essa especificidade o fato de ser adotadas oficialmente pelas Escolas Públicas do estado de Pernambuco.

Acredita-se que o objeto deste texto pode colaborar para reflexões críticas em relação ao tratamento que os Livros Didáticos de Língua Portuguesa têm dado ao ensino da produção textual, em especial, com o olhar voltado à progressão dos gêneros textuais. Sob esse ponto de vista, tanto os Parâmetros Curriculares Nacionais de Língua Portuguesa (2012) quanto a Base Curricular de Pernambuco (2012) orientam que as propostas de escrita organizem-se tendo como referência os gêneros textuais, pois se acredita que, dessa forma, os estudantes serão capazes de interagir em situações mediadas pela linguagem oral e escrita.

A prática de produção de texto sob o viés da Progressão de Gêneros

118 Textuais é uma temática pouco investigada nas pesquisas que tratam acerca da produção de texto, conforme se comprova em um levantamento realizado em anais da Associação Nacional de Pós-Graduação e Pesquisa em Educação dos anos 2012, 2013 e 2014, em que foram encontrados doze estudos sobre a temática da escrita. Verificou-se, com base na análise dos títulos e dos resumos desses trabalhos, que quatro tratam acerca do tema da produção de texto escrita. Observou-se que o foco se dá na análise e avaliação dos textos produzidos pelos alunos, assim como na investigação de como as condições de produção auxiliam no processo da escrita. Verificou-se que desses quatro, um aborda o tema da progressão: "Leitura, compreensão e produções textuais: progressão desses eixos de ensino de Língua Portuguesa no $1{ }^{\circ}$ ciclo" da autora Solange Oliveira (OLIVEIRA, 2013 ), entretanto, a autora toma a progressão na perspectiva dos ciclos, ou seja, sob um viés temporal. Observaram-se, também, artigos publicados nos anais do Congresso de Leitura (COLE), dos anos 2012 e 2013. Nesse evento, foram encontrados 28 artigos cujos títulos traziam o tema da produção de texto escrito ou ensino de escrita, entretanto a ênfase dos estudos se dá na perspectiva da análise, avaliação e reescrita dos texłos. Não 
se observou, portanto, a reflexão sobre a produção textual na perspectiva da progressão dos gêneros.

No modelo de redação, costuma-se solicitar ao aluno que ele redija um texto acerca de um tema determinado ou "tema livre", em que eles escoIhem sobre o que vão falar, ainda que não saibam muito bem como fazê-lo. Trata-se do que Beth Marcuschi e Cavalcante (2005) chamaram de redação clássica ou endógena, um modelo de escrita tipicamente produzido na escola, que se refere a um tipo de prática escrita em que não há preocupação com as condições para a produção textual, realizada, apenas, para cumprimento das tarefas propostas pelo docente que faz a correção do material.

Distanciando-se da perspectiva de redação escolar e aproximando-se da concepção de produção de texto guiada pela perspectiva de progressão dos gêneros, empregou-se sobre os dados coletados, a partir da obra didática intitulada Jornadas.port-Língua Portuguesa, cujo critério de escolha foi o fato de ser um livro aprovado no Programa Nacional do Livro Didático de 2012, além de anunciar em sua base teórica o ensino da língua na perspectiva da progressão; o olhar prevalentemente qualitativo, uma vez que a pesquisa qualitativa tem base nas teorias críticas, que, por sua vez, considera a realidade um processo em movimento, em mutação. Numa abordagem qualitativa "[...] o autor interpreta e traduz em um texto, zelosamente escrito, com perspicácia e competência científica, os significados patentes e ocultos do seu objeto de estudo" (CHIZOTI, 2003, p. 23).

Organiza-se este artigo, inicialmente, propondo-se uma discussão acerca do conceito de produção textual à luz da progressão de gêneros textuais, já que se trata do objeto de investigação deste artigo. Acredita-se que a progressão a partir do agrupamento de gêneros textuais, de modo geral, configura uma ferramenta pertinente para o ensino não só da produção de texto, mas também de todos os outros eixos da língua (leitura, oralidade, análise linguística). Em seguida, apresenta-se a análise dos dados investigados tomando-se como referência um conjunto de atividades presentes na coleção do $9^{\circ}$ ano do Ensino Fundamental. Por fim, têm-se algumas considerações finais. 


\section{Produção de texto e progressão de gêneros textuais: olhares sobre essas teorias}

Durante longo tempo, o trabalho com produção de texto na escola aconteceu de forma descontextualizada sem que fossem explícitas as condições de produção, como mostram estudos realizados por Gomes (20 11 ) e Milanezi (2012) entre outros. Não se costumava dar importância ao anteprojeto de escrita dos alunos, ou seja, ao processo de realização do texto. A descontextualização do trabalho com a produção escrita também era perceptível nos livros didáticos de língua portuguesa, como apontam estudos desenvolvidos por Beth Marcuschi e Leal (2009). A partir das contribuições oferecidas pelos Parâmetros Curriculares Nacionais (BRASIL, 1998), como, por exemplo, a proposta de ensino da língua com base no estudo dos gêneros textuais e em decorrência das mudanças ao longo dos anos no Programa Nacional do Livro Didático, iniciou-se um processo de transformação nas orientações sobre a produção de texto que foram sendo, paulatinamente, expostas nos mais variados materiais didáticos, entre eles, o livro.

A prática de produção de texto, conforme Beth Marcuschi e Ferraz 120 (2009), envolve a seleção do gênero a ser trabalhado; o tema a ser desenvolvido; a compreensão de que haverá um leitor a quem o texto se destina; a atenção para o registro linguístico a ser considerado; a percepção do ambiente no qual o texto vai circular e ser lido; o conhecimento do suporte em que o texto vai ser publicado. Todos esses elementos se encontram interligados e são essenciais para o processo de produção textual dos alunos.

Tomando como base esses critérios discutidos pelas autoras acima citadas, deve-se considerar que a seleção dos gêneros a ser trabalhados no livro ou na prática docente pode ser delineada por uma organização de "[...] gêneros que tenham semelhanças entre si e com gêneros diferentes que proporcionem possibilidade de reflexão sobre diversas dimensões da nossa linguagem" (MENDONÇA; LEAL, 2005, p. 64) sob esse olhar.

A progressão ocorre em torno dos gêneros textuais. É a partir dessa estratégia do agrupamento de gêneros que a progressão pode ser construída conforme se pode observar no agrupamento proposto por Dolz e Schneuwly (2011). 


\section{Quadro 1}

Agrupamento de Gêneros Textuais

\begin{tabular}{|c|c|c|}
\hline $\begin{array}{c}\text { Domínios sociais de } \\
\text { comunicação }\end{array}$ & $\begin{array}{c}\text { Capacidades de linguagens } \\
\text { dominantes }\end{array}$ & $\begin{array}{c}\text { Exemplos de gêneros orais } \\
\text { e escritos }\end{array}$ \\
\hline Cultura literária ficcional & $\begin{array}{l}\text { NARRAR } \\
\text { Mimeses da ação através } \\
\text { da criação de intriga. }\end{array}$ & $\begin{array}{l}\text { Conto maravilhoso } \\
\text { Fábula } \\
\text { Lenda } \\
\text { Narrativa de aventura } \\
\text { Narrativa de ficção científica } \\
\text { Narrativa de enigma } \\
\text { Novela fantástica } \\
\text { Conto parodiado }\end{array}$ \\
\hline $\begin{array}{c}\text { Domínios sociais de } \\
\text { comunicação }\end{array}$ & \begin{tabular}{|c|}
$\begin{array}{c}\text { Capacidades de linguagem } \\
\text { dominantes }\end{array}$ \\
\end{tabular} & \begin{tabular}{|c|} 
Exemplos de gêneros orais \\
e escritos
\end{tabular} \\
\hline $\begin{array}{l}\text { Documentação e memori- } \\
\text { zação de ações humanas }\end{array}$ & \begin{tabular}{l}
\multicolumn{1}{c}{ RELATAR } \\
Representação pelo discurso \\
de experiências vividas, \\
situadas no tempo.
\end{tabular} & $\begin{array}{l}\text { Relato de experiência vivida } \\
\text { Relato de viagem } \\
\text { Testemunho } \\
\text { Curriculum vitae } \\
\text { Notícia } \\
\text { Reportagem } \\
\text { Crônica esportiva } \\
\text { Ensaio biográfico } \\
\end{array}$ \\
\hline $\begin{array}{l}\text { Discussão de problemas } \\
\text { sociais controversos }\end{array}$ & $\begin{array}{l}\text { ARGUMENTAR } \\
\text { Sustentação, refutação e } \\
\text { negociação de tomadas de } \\
\text { posição. }\end{array}$ & $\begin{array}{l}\text { Texto de opinião } \\
\text { Diálogo argumentativo } \\
\text { Carta do leitor } \\
\text { Carta de reclamação } \\
\text { Deliberação informal } \\
\text { Debate regrado } \\
\text { Discurso de defesa (adv.) } \\
\text { Discurso de acusação (adv.) }\end{array}$ \\
\hline $\begin{array}{l}\text { Transmissão e construção } \\
\text { de saberes }\end{array}$ & $\begin{array}{l}\text { EXPOR } \\
\text { Apresentação textual de dife- } \\
\text { rentes formas dos saberes. }\end{array}$ & $\begin{array}{l}\text { Seminário } \\
\text { Conferência } \\
\text { Artigo ou verbete de } \\
\text { enciclopédia } \\
\text { Entrevista de especialista } \\
\text { Tomada de notas } \\
\text { Resumos de textos "expositi- } \\
\text { vos" ou explicativos } \\
\text { Relatório científico } \\
\text { Relato de experiência } \\
\text { científica }\end{array}$ \\
\hline
\end{tabular}


Produção de texto no contexto da progressão dos gêneros textuais: proposições do livro didático

\begin{tabular}{|c|c|l|}
\hline $\begin{array}{c}\text { Domínios sociais de } \\
\text { comunicação }\end{array}$ & $\begin{array}{c}\text { Capacidades de linguagem } \\
\text { dominantes }\end{array}$ & $\begin{array}{l}\text { Exemplos de gêneros orais } \\
\text { e escritos }\end{array}$ \\
\hline Instruções e prescrições & $\begin{array}{c}\text { DESCREVER AÇÕES } \\
\text { Regulação mútua de } \\
\text { comportamentos. }\end{array}$ & $\begin{array}{l}\text { Instruções de montagem } \\
\text { Receita } \\
\text { Regulamento } \\
\text { Regras de jogo } \\
\text { Instruções de uso } \\
\text { Instruções }\end{array}$ \\
\hline
\end{tabular}

Fonte | Dolz e Schneuwly (2011, p. 51)

Dolz e Schneuwly entendem que o agrupamento dos gêneros atende a três critérios fundamentais para a sua construção, ou seja, é necessário que eles:

1. correspondam às grandes finalidades sociais legadas ao ensino, respondendo às necessidades de linguagem em expressão escrita e oral, em domínios essenciais da comunicação em nossa sociedade (inclusive a escola);

2. retomem, de modo flexível, certas distinções tipológicas que já figuram em numerosos manuais e guias curriculares;

3. sejam relativamente homogêneos quanto às capacidades de linguagem dominantes implicadas na mestria dos gêneros agrupados (DOLZ; SCHNEUWLY, 201 1, p. 49).

Apresenta-se, nesse tripé, o que Mendonça e Leal (2005, p. 64) chamam de "aprendizagem em espiral", segundo a qual um mesmo gênero poderia ser revisitado em diferentes momentos da escolarização, seja no mesmo ano escolar/ciclo ou em anos/ciclos diferentes, "[...] de modo que, a cada momento, outra abordagem fosse feita, cada vez mais complexa ao longo dos anos". Nesse sentido, planejar o ensino dos eixos da língua lleitura, análise linguística, oralidade e produção de texto) a partir do estudo de gêneros textuais, com atenção para a progressão, é dialogar com as sequências reais de ensino, ou seja, com "sequência de atividades e operações" com que o professor pretende fazer avançar os alunos (DOLZ; SCHNEUWLY, 201 1, p. 3).

Com base nessas sequências de atividades, este trabalho procura enfatizar as propostas de produção escrita no livro didático, buscando tecer o perfil de como essas propostas são apresentadas. 
Seguem as estratégias de produção textual apresentadas pelo Livro Didático, corpus de investigação deste trabalho.

\section{Análise do Livro Didático: um olhar sobre a produção de texto na perspectiva da progressão de gêneros textuais}

Algumas questões basilares são apresentadas nesse processo analítico do trabalho em tela: a) qual o lugar da produção de texto na coleção? Como se dá o agrupamento dos gêneros, no âmbito da produção textual? b) Como ocorrem as propostas de escrita à luz da progressão textual? Para responder a essas perguntas, propõe-se a análise do livro didático com base em duas categorias: 1 - agrupamento dos gêneros textuais presente no livro; e 2 - propostas de produção escrita presentes na obra. A relação entre essas categorias possibilitará a análise das estratégias para a progressão de gêneros textuais como suporte para o desenvolvimento do trabalho com a produção escrita.

\section{Agrupamentos de gêneros textuais}

Na obra analisada, as autoras optam por agrupar os gêneros considerando os domínios sociais de comunicação, conforme apregoam Dolz e Schneuwly (201 1), bem como considerando as esferas de circulação dos textos, uma proposta presente no âmbito dos Parâmetros Curriculares Nacionais (BRASIL, 2012) (vale destacar que a obra didática anuncia em seu referencial teórico que constrói as atividades buscando o desenvolvimento de habilidades e competências linguísticas, como se pode ver no exemplo ilustrado, assim como em todas as outras unidades).

Este artigo direciona o seu olhar para a organização dos gêneros a partir dos domínios, refletindo sobre as ordens defendidas no referencial teórico presente neste artigo.

Abaixo segue um quadro quantitativo acerca do agrupamento dos gêneros textuais presentes no Livro Didático, no qual pode se ver um mapeamento dos gêneros textuais abordados no livro a partir do eixo em que se inserem. Dessa maneira, constata-se que a obra promove uma articulação entre os eixos da língua, visando contribuir para o processo da produção escrita. 
Quadro 2

Agrupamento de Gêneros Textuais no Livro Didático

\begin{tabular}{|c|c|c|c|}
\hline Unidade & Eixos & $\begin{array}{c}\text { Gêneros que colaboram para o } \\
\text { processo de produção }\end{array}$ & $\begin{array}{l}\text { Gêneros indicados } \\
\text { para a produção }\end{array}$ \\
\hline \multirow{4}{*}{$1^{\circ}$} & Leitura & Conto (p. 14) & \multirow{4}{*}{$\begin{array}{l}\text { Miniconto (produção } \\
\text { escrita, p. 24) }\end{array}$} \\
\hline & Leitura & Minicontos (p.22-23) & \\
\hline & $\begin{array}{l}\text { Produção } \\
\text { escrita }\end{array}$ & Minicontos (p.24) & \\
\hline & Leitura & Conto (p.34) & \\
\hline \multirow{6}{*}{$2^{\circ}$} & Leitura & Propaganda publicitária (p. 52) & \multirow{6}{*}{$\begin{array}{l}\text { Folder de divulgação } \\
\text { (folder, produccão oral e } \\
\text { escrita, p. 66) }\end{array}$} \\
\hline & Leitura & Biografia sobre "Einstein" (p. 54) & \\
\hline & Leitura & Gráfico (p. 57) & \\
\hline & Leitura & Propaganda publicitária (p. 58) & \\
\hline & Leitura & Folheto (saúde, p. 62) & \\
\hline & $\begin{array}{c}\text { Produção } \\
\text { escrita }\end{array}$ & Folder (p. 66) & \\
\hline \multirow{4}{*}{$3^{\circ}$} & Leitura & $\begin{array}{l}\text { Relatório escolar de experiência } \\
\text { (p.82) }\end{array}$ & \multirow{4}{*}{$\begin{array}{l}\text { Comentário (produção } \\
\text { oral e escrita, p. 91) e } \\
\text { Relatório de visita (pro- } \\
\text { dução escrita, p. 102) }\end{array}$} \\
\hline & Leitura & $\begin{array}{c}\text { Reportagem (de revista científica } \\
\text { sobre "Experiência" (p. 85) }\end{array}$ & \\
\hline & Leitura & Noticia (site p.89-90) & \\
\hline & $\begin{array}{l}\text { Produção } \\
\text { oral }\end{array}$ & Comentário (p. 91) & \\
\hline \multirow{5}{*}{$4^{\circ}$} & Leitura & Letra de samba-enredo (p. 118$)$ & \multirow{5}{*}{$\begin{array}{l}\text { Letra de rap (produção } \\
\text { escrita e oral, p. 139) }\end{array}$} \\
\hline & Leitura & $\begin{array}{c}\text { Texto informativo sobre "Escola } \\
\text { de Samba" (p. 120) }\end{array}$ & \\
\hline & Leitura & Comentário (p. 121) & \\
\hline & Leitura & $\begin{array}{l}\text { Textos informativos sobre a "im- } \\
\text { portância e temáticas presentes } \\
\text { em sambas-enredo" (p. 122) }\end{array}$ & \\
\hline & Leitura & Samba-enredo (p. 125) & \\
\hline
\end{tabular}




\begin{tabular}{|c|c|c|c|}
\hline \multirow{5}{*}{$4^{\circ}$} & Leitura & Letra de rap (p. 134) & \multirow{5}{*}{$\begin{array}{l}\text { Letra de rap (produção } \\
\text { escrita e oral, p. 139) }\end{array}$} \\
\hline & Leitura & $\begin{array}{c}\text { Texto informativo sobre o "grafite } \\
\text { e a dança de rua" (p. 137) }\end{array}$ & \\
\hline & Leitura & $\begin{array}{c}\text { Texto informativo sobre o "grafite } \\
\text { e a dança de rua" (p. 137) }\end{array}$ & \\
\hline & $\begin{array}{l}\text { Produção } \\
\text { escrita } \\
\end{array}$ & Letra de rap (p. 139) & \\
\hline & $\begin{array}{l}\text { Produção } \\
\text { escrita } \\
\end{array}$ & Tira humorística (p. 140) & \\
\hline \multirow{9}{*}{$5^{\circ}$} & Leitura & Artigo de opinião (p. 156) & \multirow{9}{*}{$\begin{array}{l}\text { Debate (produção oral, } \\
\text { p. } 168 \text { ) e artigo de opi- } \\
\text { nião (produção escrita, } \\
\text { p. 182) }\end{array}$} \\
\hline & Leitura & Canção (p. 159) & \\
\hline & Leitura & Tira humorística (p. 162) & \\
\hline & Leitura & Conto (p. 167) & \\
\hline & $\begin{array}{l}\text { Produção } \\
\text { oral }\end{array}$ & Tira humorística (p. 168) & \\
\hline & Leitura & Poema (p. 177) & \\
\hline & Leitura & Poema (p. 179) & \\
\hline & Leitura & $\begin{array}{c}\text { Propaganda publicitária (p. } \\
181 \text { ) }\end{array}$ & \\
\hline & $\begin{array}{c}\text { Produção } \\
\text { escrita }\end{array}$ & Carta de leitor e notícia (p. 182) & \\
\hline \multirow{7}{*}{$6^{\circ}$} & Leitura & Roteiro de filme (p. 192) & \multirow{7}{*}{$\begin{array}{l}\text { Roteiro de filme (produ- } \\
\text { ção escrita, p. 24) }\end{array}$} \\
\hline & Leitura & Canção (p. 201) & \\
\hline & Leitura & Sinopses de filmes (p. 207-208) & \\
\hline & Leitura & Campanha publicitária (p. 209) & \\
\hline & Leitura & $\begin{array}{l}\text { Roteiro de propaganda para TV } \\
\text { (p. 216) }\end{array}$ & \\
\hline & $\begin{array}{l}\text { Produção } \\
\text { escrita }\end{array}$ & $\begin{array}{l}\text { Trecho do conto "UTI- Unidade } \\
\text { de Terapia Intensiva" (p.224) }\end{array}$ & \\
\hline & $\begin{array}{l}\text { Produção } \\
\text { escrita }\end{array}$ & $\begin{array}{l}\text { Conto "O homem nu" de } \\
\text { Fernando Sabino (p. 226) }\end{array}$ & \\
\hline
\end{tabular}


Produção de texto no contexto da progressão dos gêneros textuais: proposições do livro didático

\begin{tabular}{|c|c|c|c|}
\hline \multirow{5}{*}{$7^{\circ}$} & Leitura & Conto de terror (p. 238) & \multirow{5}{*}{$\begin{array}{l}\text { Conto de terror (produ- } \\
\text { ção escrita, p. 272) }\end{array}$} \\
\hline & Leitura & $\begin{array}{c}\text { Texto informativo sobre temáticas } \\
\text { literárias (p. 253) }\end{array}$ & \\
\hline & Leitura & Notícia (p. 254) & \\
\hline & Leitura & Conto de humor (p. 264) & \\
\hline & $\begin{array}{l}\text { Produção } \\
\text { escrita }\end{array}$ & Trecho de um conto (p. 272) & \\
\hline \multirow{6}{*}{$8^{\circ}$} & Leitura & Editorial (p. 282) & \multirow{6}{*}{$\begin{array}{l}\text { Editorial (produção } \\
\text { escrita, p. 294) }\end{array}$} \\
\hline & Leitura & $\begin{array}{l}\text { Trecho de uma entrevista e pro- } \\
\text { paganda publicitária (p. 286) }\end{array}$ & \\
\hline & Leitura & $\begin{array}{l}\text { Texto explicativo sobre o gênero } \\
\text { editorial (p. 287) }\end{array}$ & \\
\hline & Leitura & Anúncios e cartazes (p. 291) & \\
\hline & Leitura & $\begin{array}{c}\text { Trechos da Cartilha do Código } \\
\text { Florestal (p. 292) }\end{array}$ & \\
\hline & Leitura & Charge e cartum (p. 302) & \\
\hline
\end{tabular}

Fonte | Delmanto e Carvalho (2012)

Ao se analisar esse quadro, percebe-se que a preparação para a produção se dá sempre a partir do eixo da leitura (presente 22 vezes e distribuídas nas oito unidades) - eixo em que os alunos têm um primeiro contato com o gênero a ser produzido posteriormente, como se pode ver no quadro. Observa-se que as atividades de leitura trazidas na obra englobam textos de diferentes gêneros que dialogam com a temática discutida na unidade. Assim sendo:

É relevante que o aprendiz da língua se defronte com diferentes textos, de diferentes gêneros textuais, e possa produzi-los, pois através dos usos destes textos e de uma prática de ensino que se aproxime dos seus usos reais, o aluno seria capaz de chegar ao domínio da produção e uso efetivo de tais gêneros textuais (SANTOS, 2007, p. 18-19).

livro, apesar de anunciar em seu aporte teórico que pretende fundamentar-se na perspectiva da progressão para o trabalho com os eixos da língua, não apresenta, de maneira unânime, uma progressão em relação aos 
gêneros agrupados, isto é, nas unidades não prevalecem gêneros de uma mesma ordem. Nesse sentido, Dolz e Schneuwly (201 1, p. 50) apontam que a progressão se dá a partir de um agrupamento de gêneros que "[...] sejam relativamente homogêneos quanto às capacidades de linguagem dominantes implicadas na maestria dos gêneros agrupados". Com exceção da primeira Unidade, em que aparece um agrupamento de gêneros da ordem do narrar: conto e miniconto; as outras sete unidades agrupam gêneros de diferentes ordens e esferas de circulação, não configurado à luz do que propõe Dolz e Schneuwly, de fato, um trabalho com a progressão.

Em contrapartida, verifica-se que tal estratégia contribui para o trabatho com a construção de texto, uma vez que prepara o aluno para o processo de produção. A preparação tem início a partir da leitura de um texto cujo gênero será estudado na unidade. Nota-se que os textos escolhidos levam em conta alguns critérios, como a diversidade de gêneros (como aparecem na tabela) e o contexto de produção. Esses critérios de seleção auxiliam na criação de situações autênticas de produção de texto no âmbito da escola, visto que "[...] não faz sentido ensinar formas textuais que não apresentam nenhuma função social e que só existem dentro dos muros da escola" (SANTOS, 2007, p. 18).

Quanto ao estudo do trabalho com o gênero principal tratado na unidade, observa-se que são contemplados os elementos que o caracterizam: conteúdo temático - estilo - construção composicional (DOLZ; SCHNEUWLY, 2011 , p. 23). Percebe-se que esse tipo de abordagem possibilita o desenvolvimento de capacidades que ultrapassam o gênero a ser aprendido e que são transferíveis para outros gêneros de uma mesma ordem ou de ordens distintas. Pode-se falar, então, em modais de progressão a partir de um agrupamento de gêneros pertencentes a diferentes ordens e esferas de circulação, mas que auxiliam na preparação para a produção e contribuem para uma aprendizagem que se dá em espiral.

Dessa maneira, nota-se que "[...] a aprendizagem da escrita não é algo que se dá de modo espontâneo, mas se constrói através de uma intervenção didática sistemática e planejada" (SANTOS, 2007, p. 22).

Pode-se constatar que o livro analisado apresenta propostas de escritas que vão de encontro a essa afirmação sinalizada pela autora, visto que 
Produção de texto no contexto da progressão dos gêneros textuais: proposições do livro didático

propõe um trabalho com a escrita capaz de proporcionar ao aluno uma aprendizagem significativa do gênero a ser produzido.

Em face do exposto acerca do agrupamento dos gêneros, analisam-se a seguir as propostas de escrita, presentes no Livro Didático.

\section{Propostas de produção textual escrita no Livro Didático}

As atividades de produção textual escrita que aparecem nas unidades são todas organizadas a partir do estudo de um gênero textual, conforme propõem os Parâmetros Curriculares Nacionais (BRASIL, 20 12); Dolz e Schneuwly (201 1); Beth Marcuschi e Ferraz (2009). Todos esses referenciais apontam que os gêneros servem como instrumento para o desenvolvimento do trabalho com a língua.

Verifica-se que os gêneros escolhidos para as produções escritas pertencem a práticas sociais da linguagem que se aproximam dos usos reais do discurso. Como se vê na proposta da segunda unidade, em que se pede que, em grupo, os alunos produzam um folder para uma campanha de prevenção contra uma doença (por eles escolhidas) para distribuir com os colegas da escola, num trabalho voluntário a serviço da comunidade. A priori, na seção "Antes de começar", é apresentado aos alunos um exemplo de folder para leitura e análise de alguns aspectos relacionados à estrutura do gênero. Na etapa "Planejando a produção", dão-se direções de como os discentes podem planejar a construção do texto: formar grupos para pesquisar imagens relacionadas ao assunto, fazer anotações sobre a doença escolhida, "recomendações" sobre a linguagem do gênero, como por exemplo: "[...] usar verbos no presente e no imperativo, slogan, frases de apelo, atentar para o público leitor etc." (DELMANTO; CARVALHO, 2012, p. 67). Concluída a primeira versão do texto, solicita-se que os alunos avaliem a produção, observando se os aspectos tratados na seção "Planejando o texto" foram contemplados, e só então realizem a reescrita. Percebe-se uma proposta firmada em uma Sequência Didática. A escrita a partir do planejamento de uma sequência didática "[... ] serve para dar acesso aos alunos a práticas de linguagens novas ou dificilmente domináveis" (DOLZ; SCHNEUWLY; NOVERRAZ, 201 1, p. 83). Observa-se, também, que a atividade para produção atende às perguntas levantadas por esses autores, na medida em que apresenta a situação para produção: 
a) Qual o gênero abordado: o folder de divulgação.

b) A quem se dirige a produção: colegas da turma e comunidade local.

c) Que forma assumirá a produção: folheto.

d) Quem participará da produção: todos os alunos.

As propostas para a produção são contextualizadas, portanto são significativos para os alunos. Nesse sentido, as propostas são de produção de texto e não do gênero redação escolar, visto que são definidas as condições para a produção: o aluno produz para interlocutores reais (colegas da turma e comunidade), o professor faz parte desse processo já que é tido como coautor do texto produzido pelos alunos. Diferente do que acontece ao se produzir uma redação, em que o texto é apenas produto e o professor, corretor e o único leitor do texto produzido.

No tópico a seguir, apresenta-se uma discussão acerca da análise de uma proposta de produção escrita com base na Progressão dos Gêneros Textuais.

Proposta de produção de texto escrito sob o viés da progressão de gêneros

Para ilustrar de forma qualitativa o tratamento dado pelo livro didático ao trato com a produção de texto à luz da progressão textual, traz-se a atividade a seguir, localizada na Unidade 1 do livro, cuja estruturação da ordem é desenhada a partir do gênero textual Miniconto, portanto, com foco na ordem do narrar.

Antes, porém, é necessário que se apresente o processo organizativo da atividade de produção textual com base na progressão dos gêneros que antecede a proposta a ser analisada neste artigo.

A proposta abaixo é apresentada aos alunos após a realização de um trabalho feito pela obra com o gênero conto, estudado na $1^{a}$ unidade, intitulada "Um conflito, uma história" (DELMANTO; CARVALHO, 2012, p. 14-21). 


\section{Imagem 1}

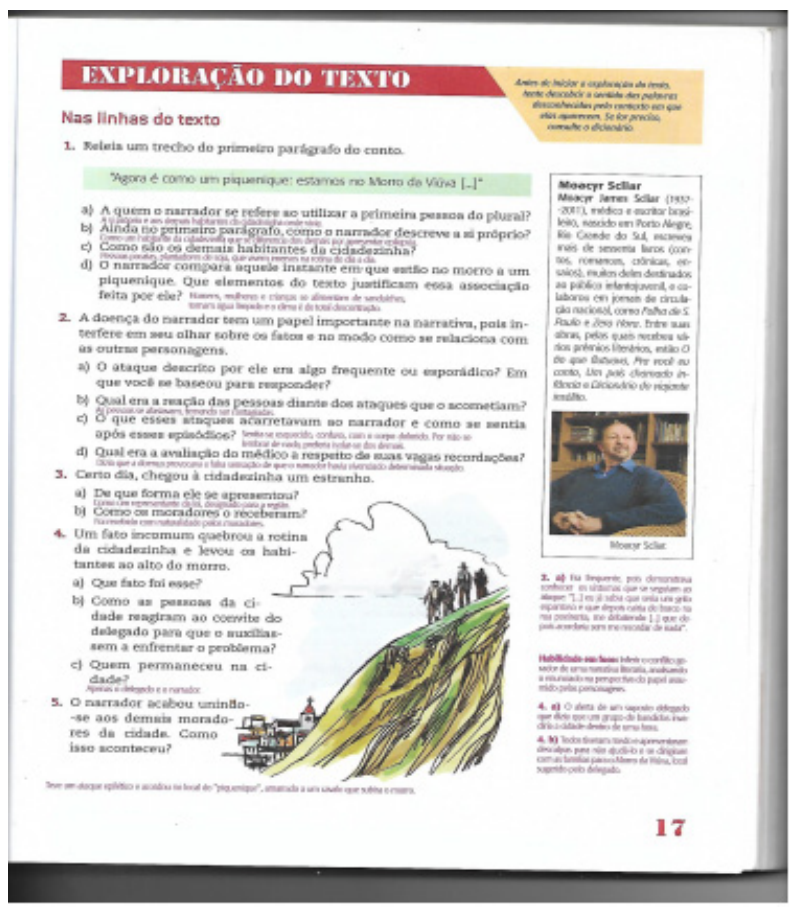

Fonte | Delmanto e Carvalho (2012)

As atividades referentes ao conto Piquenique, de Moacyr Scliar aparecem na seção Exploração do Texto (nas subseções: Nas linhas do texto, "Nas entrelinhas do texto", "Além das linhas do texto", "Como o texto se organiza" e "Recursos linguísticos"). Na subseção "Nas linhas do texto" tem-se uma atividade de interpretação textual cuja finalidade é localizar e comparar informações referentes ao conto lido. As perguntas formuladas visam ao estudo do texto e ao desenvolvimento da habilidade de inferir acerca do conflito gerador da narrativa literária, conforme se vê na imagem.

No primeiro quesito da seção "Nas entrelinhas do texto", por exemplo, as perguntas são relacionadas a elementos organizacionais do texto: a) características dos personagens; b) espaço; cl tempo. A questão 4 trata dos tipos de narrador; a 5 do enredo, e a 6 do desfecho do conto. Em "Recursos linguísticos", a atividade tem como foco a justificativa do uso de determinados recursos da língua na construção do gênero analisado. As habilidades desenvolvidas a partir desse estudo serão imprescindíveis para a construção do texto 
escrito: eis a aprendizagem "em espiral" proporcionada a partir desse agrupamento de gêneros da ordem do narrar (conto e miniconto).

Após as atividades propostas na seção "Exploração do Texto", os alunos são solicitados à produção do gênero miniconto, estudado e analisado na seção "Depois da Leitura" (DELMANTO; CARVALHO, 2012, p. 22).

\section{Imagem 2}



Fonte | Delmanto e Carvalho (2012) 


\section{Imagem 3}

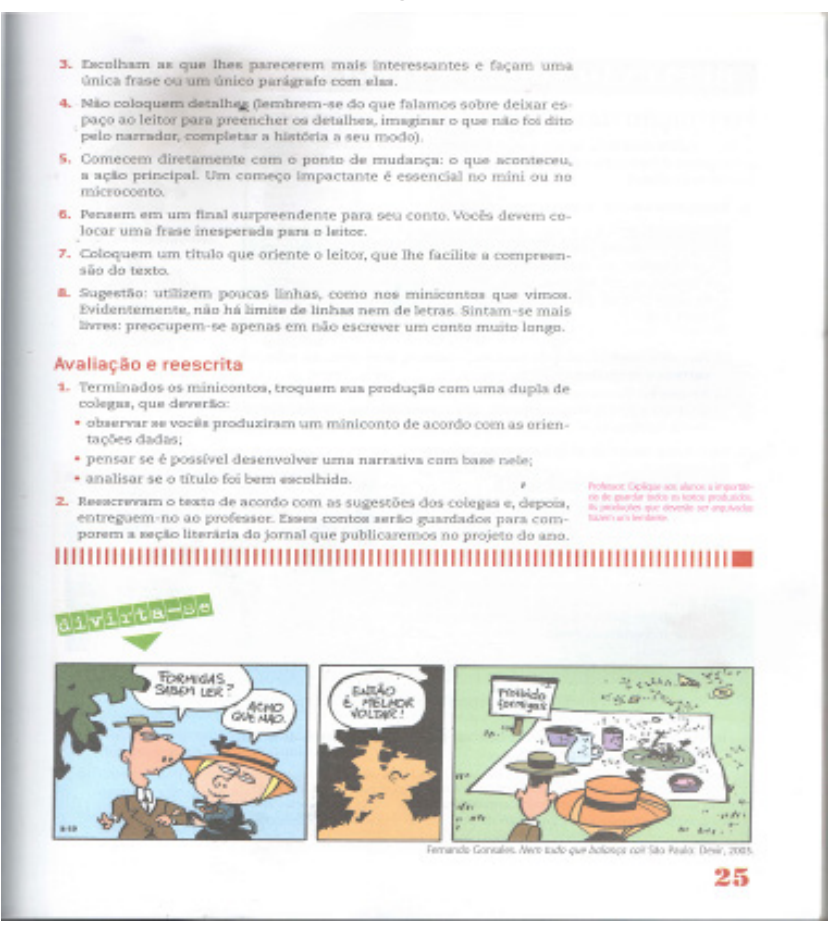

A proposta de atividade para a produção é organizada a partir dos seguintes elementos:

1. Público-alvo e Suporte textual: a produção será apresentada aos colegas da turma e o suporte de circulação será o jornal da classe, no final do ano, de acordo com o Projeto do ano letivo, a saber: a construção de um jornal. Vê-se, aqui, que a produção dos alunos terá um leitor real capaz de dialogar com seu texto (GUEDES, 2009), ou seja, a produção terá sentido na medida em que não será lida apenas por um professor corretor, mas também por interlocutores. Dessa maneira, o aluno, produtor do texto, entende que seu projeto de dizer é significativo, uma vez que tem significado para si e para o outro. Definido o público-alvo e o suporte, são apresentados modelos do gênero a ser produzido, como mostra o tópico a seguir.

2. Modelos de Gênero: são mostrados três microcontos para leitura, como observado na página 24, para análise e socialização em dupla. Vê-se que, nesse processo de preparação, é preciso "oferecer um material rico em textos 
de referência, escritos e orais, nos quais os alunos possam inspirar-se para suas produções" (DOLZ; SCHNEUWLY; NOVERRAZ, 2011 p. 82), estratégia considerada como indispensável para o trabalho com gêneros orais ou escritos. De acordo com esses autores, as atividades de observação e análise de textos servem para pôr em evidência certos aspectos do funcionamento textual, caminho este trilhado pela obra analisada. Definidas essas etapas de preparação para a produção escrita, é proposto um estudo da tipologia textual narrativa, como se pode ver na próxima etapa.

3. Estrutura do Texto Narrativo: a atividade revisa algumas características dessa tipologia textual já trabalhadas durante toda a unidade: narrador, conflito, personagens, brevidade. Por serem as tipologias textuais (também chamadas de capacidades discursivas) "[...] reguladoras poderosas e que são transversais em relação aos gêneros [...]" (DOLZ; SCHNEUWLY, 201 1, p. 33), é imprescindível que não se trate delas ao se estudar um gênero do discurso.

4. Planejamento do Texto: nesse momento da preparação, é apresentado um plano de trabalho acerca do gênero a ser produzido. São definidas as formas de produção do texto (se individual, em dupla ou coletiva) e de organização do texto; são elencados os critérios de avaliação e apresentadas sugestões para a reescrita.

a) Organização dos alunos: em dupla.

b) Organização sequencial do texto: sugere-se que os alunos partam de uma ideia simples e a relacione a outras para que escolham a mais interessante e cheguem a um único parágrafo. Em seguida, pede-se que comecem pela ação principal para impactar o leitor. Deverão pensar num final surpreendente e colocar um título. Nessa etapa, consoante apregoam Dolz, Schneuwly e Noverraz (201 1, p. 88), os alunos são levados a estruturar seus textos de acordo com uma finalidade específica (surpreender o leitor) e de acordo com o destinatário (os colegas da turma). Portanto, o aluno arquiteta seu texto conforme a situação de comunicação apresentada. Nesse sentido, a produção é contextualizada.

c) Avaliação: sugere-se, inicialmente, que as duplas troquem seus textos com outra dupla para observar se foi produzido um miniconto de acordo com as orientações dadas; se é possível desenvolver uma narrativa com base nele; e solicita-se que avaliem a adequação do título. 
Produção de texto no contexto da progressão dos gêneros textuais: proposições do livro didático

d) Reescrita: a reescrita deverá ser feita de acordo com as sugestões feitas pelos colegas que fizeram a avaliação. Nessa etapa, orienta-se para a reelaboração do texto produzido.

É possível observar que a proposta de produção textual presente na obra analisada oportuniza ao aluno o desenvolvimento de um trabalho sistemático com a escrita visto que possibilita, a priori, o trabalho com o gênero textual a ser produzido, ao propor uma atividade de identificação de algumas características recorrentes do gênero microconto; além disso, deixa claro quem serão os leitores das produções - professor e colegas de turma; o suporte de divulgação/veículo de circulação - seção literária do jornal a ser produzido no Projeto do Ano; orienta a construção do "projeto de dizer" dos alunos sem deixar de colaborar para a autonomia do processo de escrita, e propõe uma atividade para a avaliação e reescrita dos textos produzidos, a troca dos textos com outra dupla e reescrita a partir das sugestões feitas pelos colegas.

Em se tratando do aspecto da progressão, a unidade agrupa gêneros da ordem do narrar que, de acordo com Dolz e Schneuwly (201 1, p. 51 ), comportam gêneros cuja capacidade de linguagem predominante é a "mime-

134 ses da ação através da criação de intriga". Ao optar por essa estratégia do agrupamento, observa-se que é possível transferir aspectos ou características apreendidas de um gênero para o outro, tais como os recursos linguístico-discursivos utilizados na composição dos gêneros, as características recorrentes presentes nos gêneros textuais (organização, estrutura, propósito comunicativo, esfera de circulação, suporte, público leitor), assim como a análise de como ocorre a construção da ordem do narrar em ambos.

\section{Considerações finais}

Este trabalho teve como objetivo investigar as estratégias didáticas utilizadas para o trabalho com a produção escrita, sob o viés da progressão de gêneros textuais, no livro didático de língua portuguesa. De todas as propostas de atividades de produção de texto analisadas na obra didática, apenas a proposta da primeira unidade se utiliza, de fato, da progressão textual como ferramenta para o trabalho com a escrita, sob a perspectiva dos domínios 
sociais de comunicação e dos aspectos tipológicos como propõem Dolz e Schneuwly (2011).

Em contrapartida, observou-se que o livro didático apresenta um trabalho com a escrita de maneira sistematizada e com foco na preparação para a produção textual. É possível afirmar que tal estratégia de ensino de produção de texto configura um importante avanço no trato dado à escrita no que se refere ao ensino/aprendizagem desse eixo da língua, já que concorre para uma prática de produção de texto que tem como foco o processo e não o resultado. Ademais, contribui para a autonomia da escrita dos alunos, visto que propicia o estudo dos gêneros textuais com base em situações reais de uso da língua.

Notou-se que o trabalho com as atividades de produção de texto está intimamente ligado ao gênero textual estudado em cada uma das unidades. A progressão textual dos gêneros textuais presente na Unidade 1 compreende a possibilidade de partilhar conhecimentos apreendidos acerca de um gênero e outro, por apresentarem características semelhantes entre si, como, por exemplo, elementos presentes nos gêneros, organização textual, estrutura, propósito comunicativo, linguagem, suporte (vale ressaltar que não se deixa de trabalhar as particularidades de cada texto apresentado para análise do gênero, nas seções Leitura 1 e 2, já que, como sugere Santos (2007, p. 26), gênero e texto são fenômenos imbricados, que devem caminhar juntos). Além disso, o trabalho também se dá em espiral no que diz respeito às habilidades linguístico-discursivas apresentadas a partir dos gêneros textuais abordados. Nesse sentido, a progressão textual aparece como sistematização temporal de ensino da produção de texto, de modo que possibilita a aprendizagem de um gênero ou de uma ordem textual (narrar).

Em síntese, verificou-se que as atividades de escrita presentes no livro procuram incentivar o professor a ser mediador desse processo e coautor do texto produzido pelos discentes. E a progressão dos gêneros? Constatou-se que, no agrupamento dos gêneros escolhidos, não predominam gêneros de uma mesma ordem (exceto na primeira unidade, como se demonstrou). De acordo com Dolz e Schneuwly (201 1, p. 104), a organização desse tipo de progressão se dá quando um mesmo gênero é trabalhado em diferentes ciclos/séries, com objetivos cada vez mais complexos, ou diferentes gêneros pertencentes a um mesmo agrupamento, em função das possibilidades de transferência que permitem. Considerando esse ponto de vista, não se pode 
afirmar que as propostas de produção de texto escrito são construídas a partir de um viés de progressão como propõem esses autores. Entretanto, pode-se falar em um modal de progressão, em que os gêneros agrupados, apesar de não pertencerem a uma mesma ordem, consideram uma diversidade textual e proporcionam uma aprendizagem "em espiral", fazendo com que os alunos sejam capazes de mobilizar conhecimentos adquiridos acerca de um determinado gênero estudado para outro. Nesse sentido, oportuniza uma produção textual significativa.

\section{Referências}

BRASIL. Parâmetros Curriculares Nacionais. Terceiro e quarto ciclos do ensino fundamental: língua portuguesa. Brasília: MEC/SEF, 1998.

Parâmetros Curriculares Nacionais. Língua Portuguesa, Ensino Fundamental. Terceiro e quarto ciclos. Brasília: MEC/SEF, 2012.

CHIZOTTI, Antonio. Pesquisa em ciências humanas e sociais. São Paulo, Cortez, 2003.

136 DELMANTO; Dileta; CARVAlHO, Laiz Barbosa de. Jornadas. port-Língua Portuguesa, $9^{\circ}$ ano, 2. ed. São Paulo: Saraiva, 2012.

DOLZ, Joaquim; SCNHEUWLY, Bernard. Gêneros orais e escritos na escola. Campinas: Mercado de Letras, 2011.

DOLZ, Joaquim; SCNHEUWLY, Bernard; NOVERRAZ, Michelle. Sequências Didáticas para o oral e a escrita: apresentação de um documento. In.: DOLZ, Joaquim; SCNHEUWLY, Bernard. Gêneros orais e escritos na escola. Campinas: Mercado de Letras, 2011.

GERALDI, João Wanderley. A aula como acontecimento. São Carlos: Pedro \& João Editores, 2010.

GUEDES, Paulo Coimbra. Da redação à produção textual: $\bigcirc$ ensino da escrita. São Paulo: Parábola, 2009.

GOMES, Jaciara Josefa. Reflexões sobre os rumos e desafios da escrita: da teoria à prática. Revista Encontros de Vista, Recife, p. 46-59, jul./dez. 2011.

KOCH, Ingedore Villaça. O texto da construção de sentidos. São Paulo: Contexto, 2003. 
$\mathrm{KOCH}$, Ingedore Villaça; ELIAS, Vanda Maria. Ler e compreender: os sentidos do texto. São Paulo: Contexto, 2015.

LEAL, Telma Ferraz; BRANDÃO, Ana Carolina Perrusi. É possível ensinar a produzir textos! Os objetivos didáticos e a questão da progressão escolar no ensino da escrita. In: LEAL, Telma Ferraz; BRANDÃO, Ana Carolina Perrusi. Produção de textos na escola: reflexões e práticas no Ensino Fundamental. Belo Horizonte: Autêntica, 2006

MARCUSCHI, Beth; FERRAZ, Telma. Produção de textos escritos: o que nos ensinam os livros didáticos do PNLD 2007. In: ROJO, Roxane; VAL, Maria da Graça Costa (Org.). Os livros didáticos de língua portuguesa no PNLD 2009. Belo Horizonte: Autêntica, 2009.

MARCUSCHI, Beth; CAVALCANTI, Marianne Carvalho Bezerra. Atividades de Escrita em Livros Didáticos de Língua Portuguesa: perspectivas convergentes e divergentes. In: VAL, Maria da Graça Costa; MARCUSCHI, Beth (Org.). Livros didáticos de língua portuguesa: letramento e cidadania. Belo Horizonte: CEALE/AUTÊNTICA, 2005.

MENDONÇA, Márcia; LEAL, Telma Ferraz. Progressão escolar e gêneros textuais. In.: SANTOS, Carmi; MENDONÇA, Márcia (orgs.). Alfabetização e letramento: conceitos e relações. Belo Horizonte: Autêntica, 2005. p. 57-71.

MILANEZI, Cynthia Nunes. Práticas de produção de textos escritos no Ensino Técnico Integrado ao Médio, 2012. Disponível em: http://35reuniao.anped.org.br/trabalhos / 111 -gt10. Acesso em: 26 dez. 2016.

OLIVEIRA, Solange Alves de. Leitura, compreensão e produções textuais: progressão desses eixos de ensino de Língua Portuguesa no $1^{\circ}$ ciclo. In.: REUNIÃO NACIONAL DA ANPED, 36; 2013 , Goiânia. Anais... Goiânia, 2013.

SOARES, M. Letramento e alfabetização: as muitas facetas. In: REUNIÃO ANUAL DA ANPED, 26; 2003, Caxambu. Anais... Caxambu: ANPEd, 2003a.

Letramento: um tema em três gêneros. Belo Horizonte: Autêntica, 1998.

PERNAMBUCO. Secretaria de Educação. Base Curricular Comum para as Redes Públicas de Ensino de Pernambuco: língua portuguesa. Recife: Secretaria de Educação, 2012.

SANTOS, Carmi Ferraz. $\bigcirc$ ensino da língua escrita na escola: dos tipos aos gêneros textuais. In.: SANTOS, Carmi Ferraz; MENDONÇA, Márcia; CAVALCANTI, Marianne C.B (Org.). Diversidade textual: os gêneros na sala de aula. Belo Horizonte: Autêntica, 2007. 
Mestranda Jéssica Pereira da Silva Universidade de Pernambuco

Programa de Pós-Graduação em Educação Grupo de Pesquisa Para a História do Português Brasileiro I PHPB-UFRPE E-mail I jessica.pereira1990@hotmail.com

Profa. Dra. Débora Amorim Gomes Costa-Maciel Universidade de Pernambuco | Campus Mata Norte Departamento de Educação Programa de Pós-Graduação em Educação Grupo de Pesquisa Práticas Discursivas, Interação Social e Ensino UPE E-mail I deboracostamaciel@gmail.com

Recebido 19 ago. 2016 Aceito 19 dez. 2016 